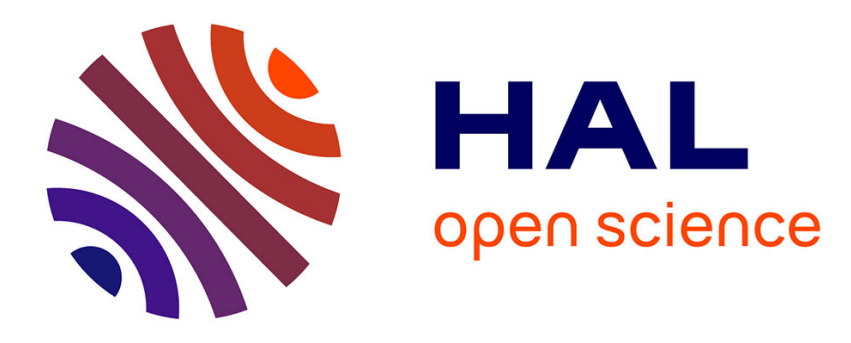

\title{
A Minoan Geometry for Bisecting and Trisecting the Right Angle
}

Amelia Carolina Sparavigna, Mauro Maria Baldi

\section{To cite this version:}

Amelia Carolina Sparavigna, Mauro Maria Baldi. A Minoan Geometry for Bisecting and Trisecting the Right Angle. 2016. hal-01294529

\section{HAL Id: hal-01294529 \\ https://hal.science/hal-01294529}

Preprint submitted on 29 Mar 2016

HAL is a multi-disciplinary open access archive for the deposit and dissemination of scientific research documents, whether they are published or not. The documents may come from teaching and research institutions in France or abroad, or from public or private research centers.
L'archive ouverte pluridisciplinaire HAL, est destinée au dépôt et à la diffusion de documents scientifiques de niveau recherche, publiés ou non, émanant des établissements d'enseignement et de recherche français ou étrangers, des laboratoires publics ou privés. 


\title{
A Minoan Geometry for Bisecting and Trisecting the Right Angle
}

\author{
Amelia Carolina Sparavigna ${ }^{1}$ and Mauro Maria Baldi ${ }^{2}$ \\ 1 Department of Applied Science and Technology, Politecnico di Torino, Torino, Italy \\ 2 Department of Control and Computer Engineering, Politecnico di Torino, Torino, Italy \\ Email: amelia.sparavigna@polito.it, mauro.baldi@polito.it
}

Submitted HAL 29/03/2016

\begin{abstract}
In a recent paper, we have shown that Egyptians of the New Kingdom were making drawings using compass and straightedge before creating the polychrome decorations of their artifact. Arguing that the use of such instruments had been previously consolidated in the eastern Mediterranean area, here we consider the possibility that the Minoan civilization had a geometry, which allowed its architects and skilled workers to bisect and trisect the right angle with compass and straightedge. To this purpose, we will analyse some decorations on artifacts and some frescoes found in the Knossos Palace of Crete and at Akrotiri, on the island of Santorini.
\end{abstract}

Keywords: Geometry, History of Science, Geometric Patterns, Compass and Straightedge Constructions, Archaeology, Minoan Civilization.

Subject Areas: Archeology, History of Science, History of Geometry.

\section{Introduction}

As discussed and shown in a previous paper [1], Egyptians of the New Kingdom were making drawings using compass and straightedge before creating the polychrome decorations of their artifacts. In [1], we have shown an overlapping circles grid drawn with compass and straightedge, made on an wooden panel which had been found in a tomb of an Egyptian architect of 14-th century BC. Of course, the use of compass is quite older, as given by the existence of perfect circular decorations on objects of about 2930-2910 BC [2,3], but the onset of using compass and straightedge together is very important because it means the first step towards an Euclidean geometry. It would be quite relevant, therefore, to find other examples such as that given in [1]; this is not easy, because artifacts were often made on perishable materials or the geometric drawing had been covered by a painted decoration.

If we have not such drawings, we can argue that a geometric construction was made if the final result of the decoration is displaying some geometric properties. Following this approach, here we aim to show that a possible use of constructions with compass and straightedge could be anterior to the artifact of the New Kingdom described in [1] and here shortly discussed in the Appendix. Examples we are here proposing are coming from the Minoan civilization and are concerning constructions to bisect and trisect the right angle, to have some almost perfect decorations found at Crete, on artifacts and in the frescoes of Knossos Palace, and in a wall-painting of Akrotiri on the island of Santorini.

It is highly probable that Minoans were able of bisecting and trisecting right angles using compass and straightedge. Among the artifacts showing this capability, one had been found in an Egyptian tomb of Nubia. This means that some knowledge of geometry developed by Minoans could had reached the Egypt or vice-versa, and that a practical geometry had been diffused and consolidated in the Mediterranean area, quite before Euclid formally stated his geometry . 


\section{Minoan civilization}

The Minoan civilization was a Bronze Age civilization that flourished on Crete and other islands of Aegean Sea, from approximately 3650 to $1400 \mathrm{BC}$ [4]. The oldest inhabitants on Crete were Neolithic farmers, as evidenced by some remains date approximately $7000 \mathrm{BC}$ [5]. In the late 3rd millennium $\mathrm{BC}$, several villages of the island turned into centers of commerce and handwork, which developed their local elites [6]. After, these local governments were replaced by the power structures that created the great palaces of the island [7]. Around $1700 \mathrm{BC}$ an earthquake, or an invasion from Anatolia [1], destroyed the palaces of Knossos and Phaistos and others. After, during the Neopalatial period, population increased again and palaces were rebuilt on a larger scale [4]. This period, that spanned 17th and 16th centuries, is considered the apex of the Minoan civilization. Another natural catastrophe, the eruption of Thera volcano, destroyed the palaces, but this time, the Minoan civilization drastically declined. The eruption devastated Thera (Santorini), with its Minoan settlement at Akrotiri. Also the northern coast of Crete was devastated by a related earthquake or tsunami [8].

The ancient Minoan palaces were rich of frescoes and decorations and beautiful decorated pottery had been found in several settlements. Not only, Minoans were able of developing and applying various architectonical solutions and technologies. For instance, they developed a system for collecting, storing and transporting surface- and ground-water resources [9], and therefore, during the Bronze Age, the Minoans had an advanced water management and sanitary techniques were practiced [9]. The palace buildings were multi-storied, which were laced with interior and exterior staircases, having light wells for the illumination of internal rooms. "Polythyrons", essentially a series of openings framed by square-sectioned wooden pillars, were used as shuttered windows to create privacy, but also to let in or keep out fresh air and light, as the seasonal conditions required.

Clearly the Minoans had also some mathematics and geometry for supporting their architecture and engineering. Here, we propose to analyze the decorations of some of their artifacts and frescoes for having some hints on their geometry. No written texts are available, and therefore these can be the only source at our disposal. In particular, we consider that they had some geometric construction with compass and straightedge, in particular for bisecting and trisecting the right angle. Let us note that arguments in this sense had been already proposed in a very interesting discussion on Minoan frescoes, [10-12], where the decorations with spirals and rosettes are seen as made with the use of templates of geometric curves. Let us also note that the Minoan techniques could had influenced the Egyptian geometry, or vice-versa, could have been developed after trading with Egypt.

\section{Arthur Evans and his documentation on the Knossos Palace}

Besides web resources, to help us in our research on the Minoan geometry are fundamental the books written by Arthur Evans. In fact, the Minoan civilization was rediscovered at the beginning of the 20th century, through the work of this British archaeologist. Sir Arthur John Evans (1851-1941) was a pioneer in the study of Aegean civilization in the Bronze Age. He is most famous for unearthing the palace of Knossos on Crete. The web site Archive.org is collecting the works of Evans on the excavations at Crete and also the Scripta Minoa, where he transcribed and organized the 3000 clay tables that he found during excavations. Some of them are now missing, and therefore his transcriptions are the only source of the marks on the tablets.

Here we use the volumes "The palace of Minos: a comparative account of the successive stages of the early Cretan civilization as illustrated by the discoveries at Knossos", volumes 1, 3 and 4, available at archive.org/details/palaceofminoscom01evanuoft, archive.org/details/palaceofminoscom03evan and archive.org/stream/cu31924081667812\#page/n401/node/2up. 


\section{Bisect angles}

Let us start our investigation on the Minoan knowledge of geometry from the problem of bisecting an angle, in particular the right angle. We can easily bisect angles or segments using compass and straightedge. Let BAC the right angle. The compass is used for having $\mathrm{AE}$ equal to $\mathrm{AD}$, first drawing the red circumference, and also $\mathrm{EF}$ and $\mathrm{DF}$ equal to ED. In fact, let us note that it is enough having $\mathrm{EF}$ equal to $\mathrm{DF}$ to find the point $\mathrm{F}$. Once $\mathrm{F}$ is given we have to draw the straight line AF which bisects the angle.

In fact, Proposition 9 of the First Book of Euclid's Elements is telling this. Let the angle BAC be the given angle. "Take an arbitrary point

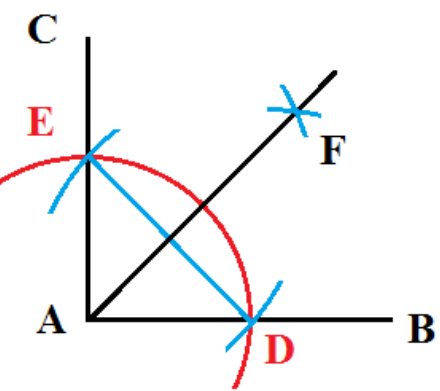
$\mathrm{D}$ on $\mathrm{AB}$. Cut off $\mathrm{AE}$ from $\mathrm{AC}$ equal to $\mathrm{AD}$, and join $\mathrm{DE}$. Construct the equilateral triangle $\mathrm{DEF}$ on $\mathrm{DE}$, and join AF. The angle BAC is bisected by the straight line AF". In his proposition, Euclid is implicitly giving us a method for constructing a template for easily bisect angles, based on three rulers having the same length (the equilateral triangle). But, in any case, the starting point is in the use of compass. However, before bisecting the right angle, we have to construct it. Right angles are obtained with compass and straightedge, when we want to have a straight line perpendicular to a given segment. In fact, if we consider again the previous construction, we immediately have how to obtain the perpendicular line. We can start from a segment and use compass to have two circles, possessing the same radius, with their centers at the ends A and B of the segment. After joining the two intersections of the circles, $\mathrm{F}$ and $\mathrm{G}$, with a straight line, we have the perpendicular to $\mathrm{AB}$.

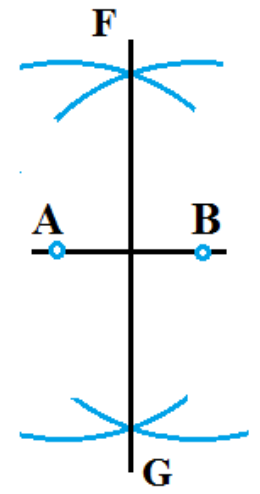

It is easy to imagine that the construction of a perpendicular to a given line with compass and straightedge was among the first geometric constructions devised in the past, probably followed by the problem of bisecting a right angle. Of course, if we know how it is possible to bisect the right angle, the generalization to a generic angle is straightforward.

Besides their uses for architecture, the constructions of perpendicular straight lines and bisection of angles are fundamental to create decorations with perfect rosettes. A rosette is a stylized flower design, used extensively in antiquity, appearing in Mesopotamia and used for decorations in Egypt and Ancient Greece. This design derives from the natural shape of botanical rosettes, formed by leaves radiating out from a part of a plant. Of course, a rosette as a decoration can be obtained with a free-hand drawing or from a geometric construction. When a rosette appears having an almost perfect design, probably it had been made using compass and straightedge for determining the directions of the leaves.

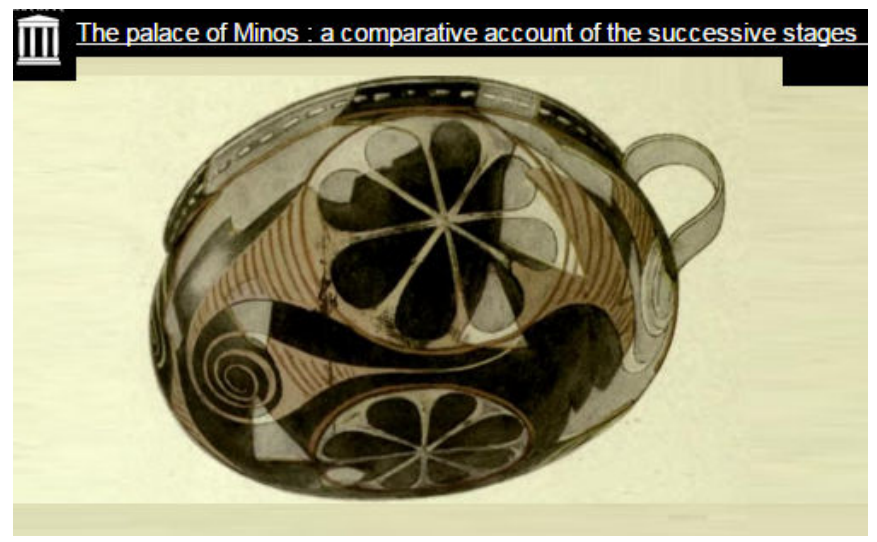

Figure 1. An “egg-shell” ware of polychrome style (MMIIa period), from Evans' book on the Knossos Palace. 

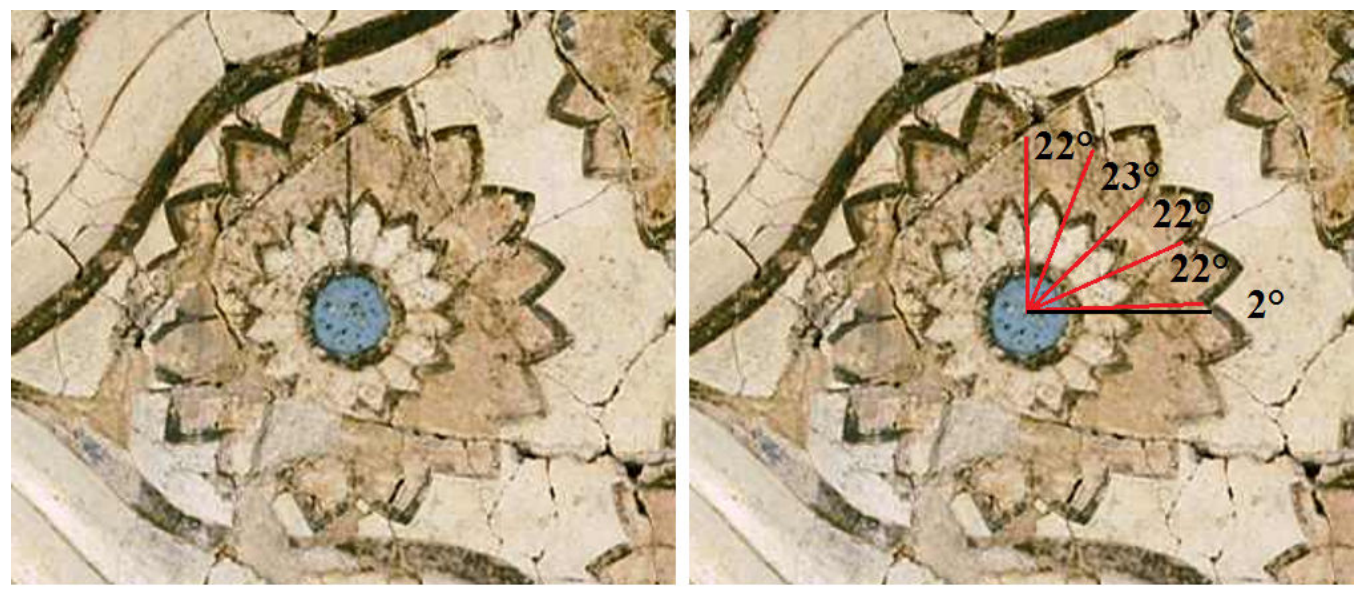

Figure 2. A rosette from a wall-painting found at Akrotiri (courtesy Wikipedia). It is clear that it was made with a geometric drawing. Note the angles the dark lines of the rosette are giving. The measure angles is given with an uncertainty of half a degree.

In the Evans' book on the Knossos Palace, we can find an image (Figure 1) showing a "egg-shell" ware of polychrome style (MMIIa period). The rosette is perfect and seems created after a geometric construction with compass and straightedge. This is not the only example of a perfect rosette. In the Figures 2 and 3, we can see details of a wall-painting from Akrotiri. It was a Minoan Bronze Age settlement on the volcanic island of Santorini. The settlement was destroyed in the eruption about 1630 BC. It was buried in the volcanic ash that preserved the remains of frescoes, objects and artworks.

In Figures 2 and 3, we can see that the rosettes were obtained from a geometric drawing, as evidenced by the black radial straight lines, emanating from the center of the rosette. After, a free-hand polychrome decoration had been applied. It seems quite reasonable that the angles had been determined using compass and straightedge, by bisecting the right angle and then by a further bisecting of the two halves. Another possibility is the existence of an instrument, a template, used for preparing the drawing. May be, this template was organized, as previously told, with rulers of the same length.
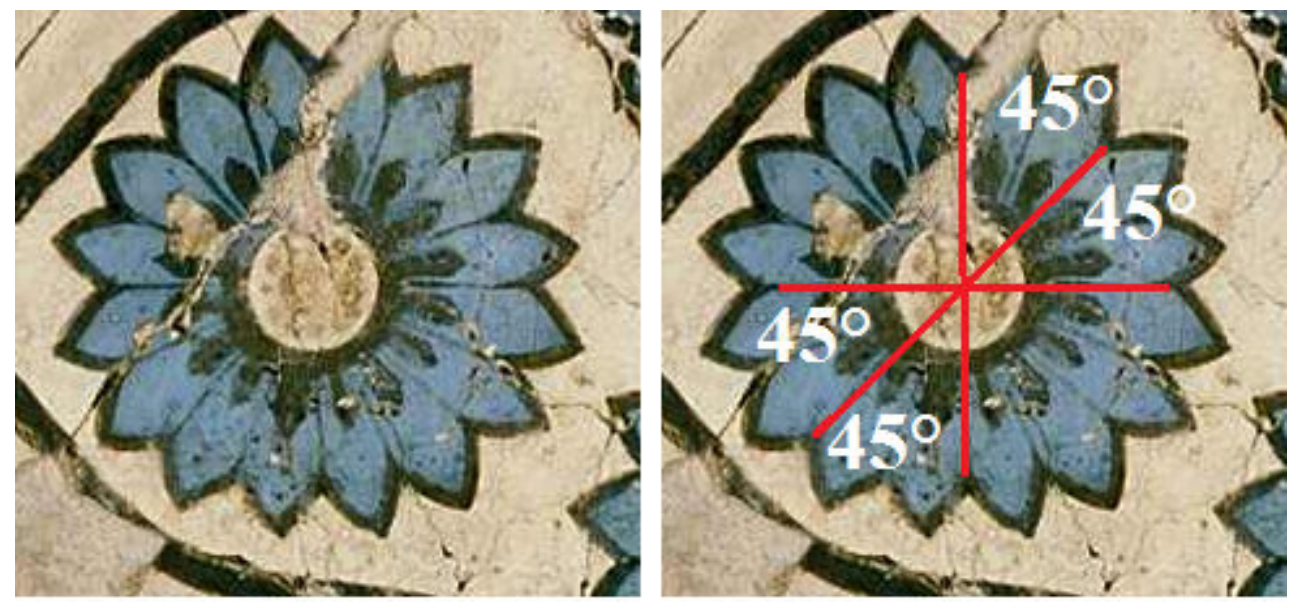

Figure 3. Another rosette from the same wall-painting from Akrotiri of Figure 2 (courtesy Wikipedia).

Let us note that, in the Akrotiri fresco, there are rosettes having precise angles, but others that are more irregular, probably due to the necessity to arrange them in the framework of the drawing. 


\section{Trisect the right angle}

This is not a difficult task, if we use a compass. In fact, trisecting a right angle is equivalent to find the six points on a given circumference, points which are the vertices of hexagons. We can open a compass and draw DE arc. Then, with the same radius of $\mathrm{BD}$ and $\mathrm{BE}$, putting the compass point in D. we can easily find Q. And then, pointing in $\mathrm{E}$, the position of $\mathrm{P}$. The straight lines $\mathrm{BP}$ and $\mathrm{BQ}$ are trisecting the
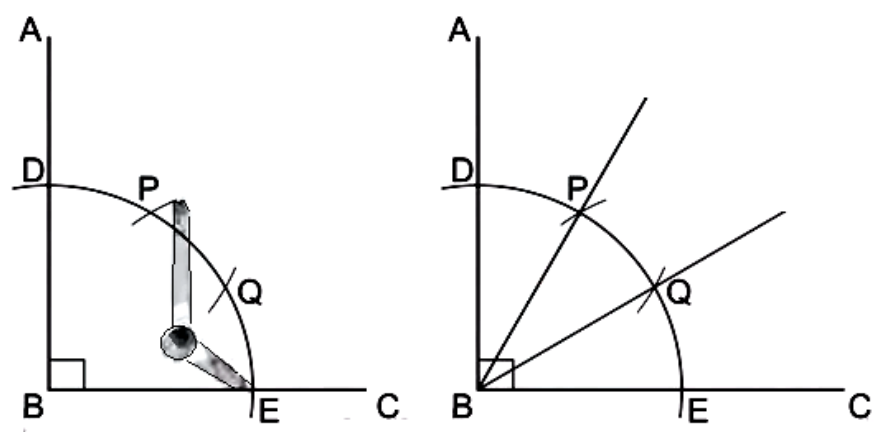
right angle.

In the Evans' books we can find several examples of frescoes in the Knossos palace, where the friezes have spirals and rosettes, and a trisection of the right angle is appearing. Unfortunately, after the discovery of the palace, Evans ordered to restore the frescoes and then we have not their original pictures. In the Figure 4, we can see the friezes of the Hall of the Double Axes, of a bathroom and of Hall of the Dolphins.
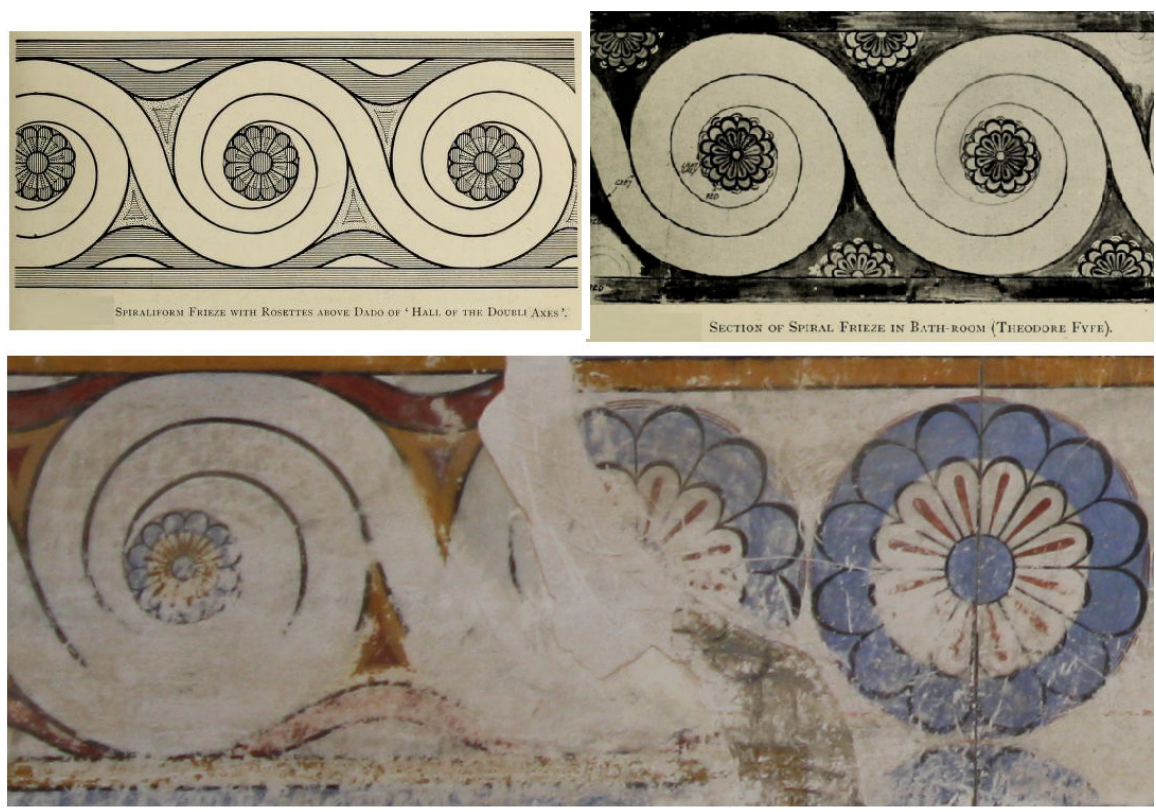

Figure 4. Friezes with spirals and rosettes of the Hall of the Double Axes, of a bathroom and of Hall of the Dolphins (courtesy Wikipedia). The rosettes show that the right angle had been trisected.

Let us also show another example of trisecting the right angle from a pottery decoration too. We can see it in the Figure 5. As explained in the Evans' book on the Knossos palace, this object was found in an Egyptian cemetery in Nubia. 


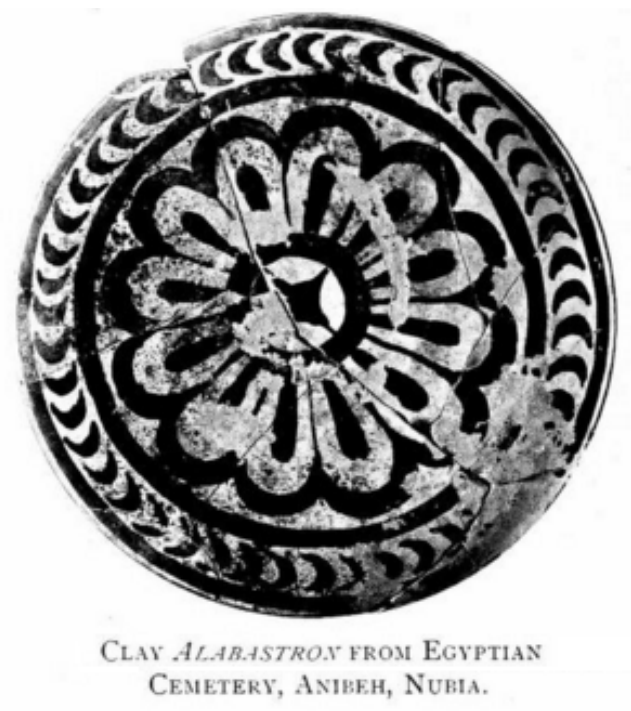

Figure 5. A beautiful geometry decoration on pottery found in an Egyptian tomb in Nubia.

This Minoan pottery found in an Egyptian tomb does not mean a direct contact between Egypt and Crete. However, Minoan wall paintings exist at Tell El-Dab'a, in a palace of the Thutmosid period. The frescoes date to the Eighteenth dynasty of Egypt, most likely during the reigns of either Hatshepsut or Thutmose III. The paintings indicate a more direct involvement of Egypt in international relations and cultural exchanges with the eastern Mediterranean [13].

The central part of the decoration shown in the Figure 5 is quite interesting. Probably it had been made with a compass, making four tangent circles having the same radius in a square packing. This figure appears also in a special object, found by Evans in the Knossos palace. It is a game board tessellated with gold, silver, ivory and rock crystal. This object, shown in the Figure 6 is a triumph of geometry.
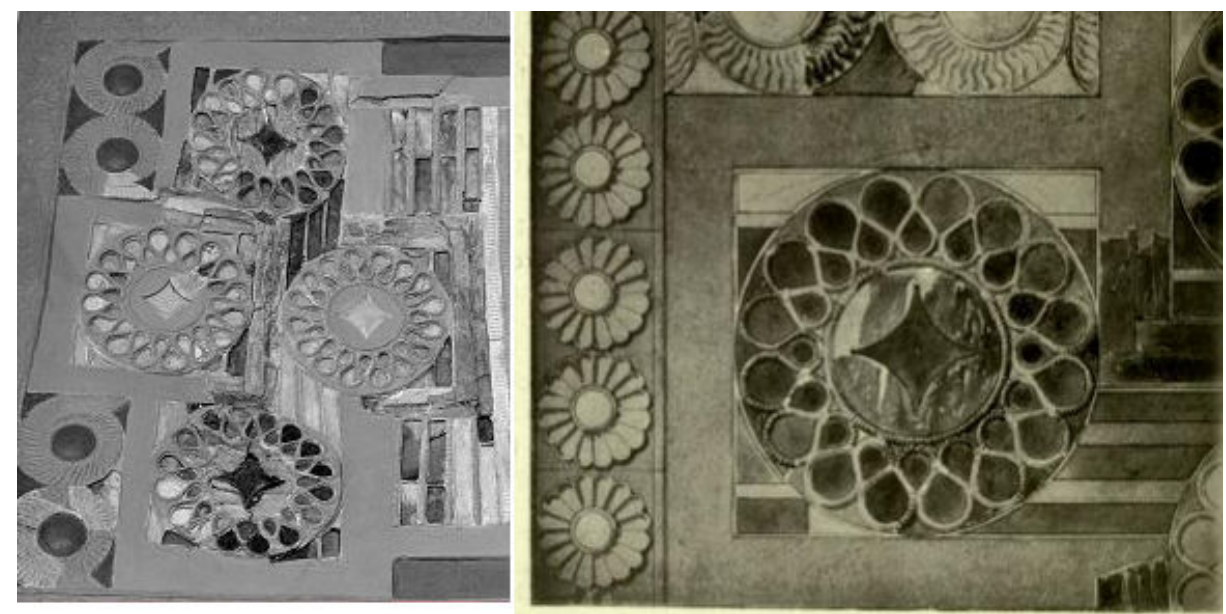

Figure 6. Details of the game board found by Evans in the Knossos palace. 


\section{Discussion}

If we suppose that, about two centuries before the date of the Egyptian artwork described in [1], the Minoans had some notions of the use of compass and straightedge, then Minoans were probably able of bisect and trisect the right angle using them. However, as told in [11], the existence of the "wall paintings don't in themselves prove that the Therans (or the Minoans) knew enough geometry to bisect angles". Accordingly to Papaodysseus [11], this is quite evident. In this paper, we have added to the existence of frescoes and artifacts, the possibility that Minoans had, like ancient Egyptians, a consolidated use of compass and straightedge. This allow us to guess that Minoans had some elementary notions of "practical" Euclidean geometry too.

Let us conclude remarking that, as told in [12], the use of some geometry for preparing templates for decorations had been first proposed by Janice Crowly [14] (unfortunately we have not yet the opportunity of studying this paper). In [12], it is reported that she analyzed the curvilinear designs occurring on Minoan seals and pottery, demonstrating that most of them derive from segments and/or combinations of circle, ellipse, triangle and arc, and that the Minoans could make a mathematical spiral. Here, we have added our contribution, pointing out that, assuming constructions with compass and straightedge being in use in the Eastern Mediterranean area, the Minoans could had been able of making specific geometric templates for their artworks.

\section{Appendix}

As discussed in [1], ancient Egyptians, masters in drawing artistic figures, were also able of making constructions using compass and straightedge. It is clearly displayed by a wood panel, covered by an overlapping circles grid decoration, found in the tomb of architect Kha. This architect served three kings of 18th dynasty, and lived about 1400-1350 BC. The Kha's Tomb, the objects of which are at the Museo Egizio, Torino, was discovered by the Italian Egyptologist Ernesto Schiaparelli in February 1906.

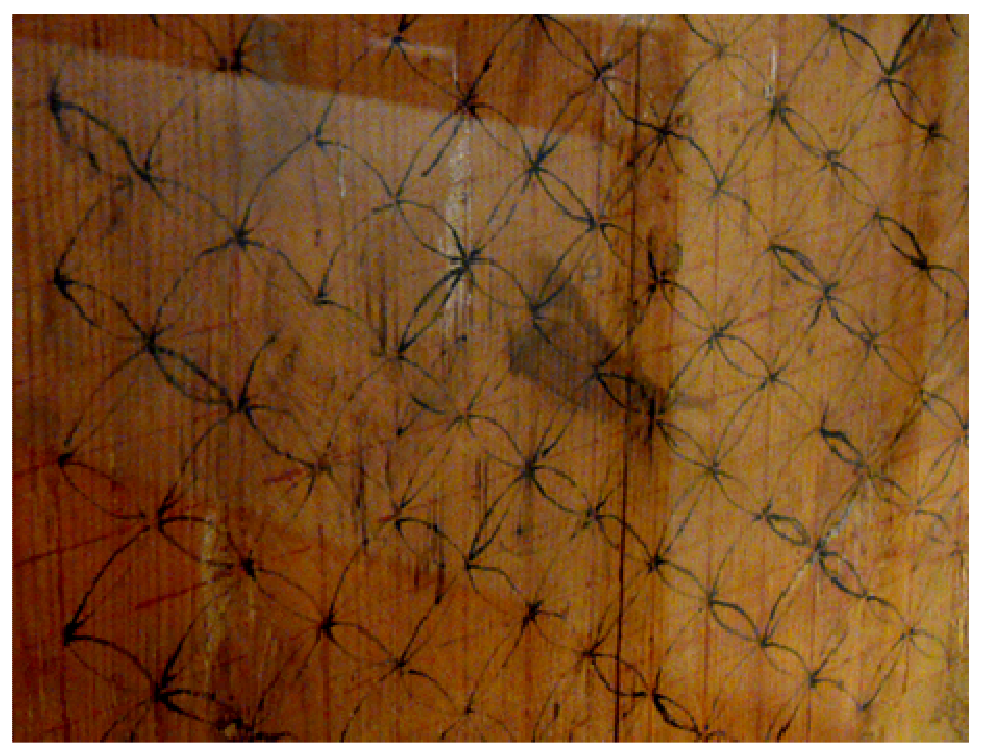

Figure 7. Wood panel found in the Kha's Tomb. Note the red lattice of parallel and perpendicular straight lines on which we find the centers of the black circles.

During Kha's life, Egypt was a powerful and wealthy country. The court of Amenhotep III, "was luxurious beyond imagination, with the wealth of the Mediterranean world flowing into Egypt's coffers" [15]. Therefore, Kha the architect lived in a privileged environment where, as we can easily imagine, 
besides the luxury and exotic goods, also knowledge and science were flowing, from the Mediterranean and Eastern countries into the cultural elite of Egypt. To the authors' best knowledge, the panel shown in the Figure 7 is the only existing example of a drawing made before painting on it a final polychrome decoration. The drawing consists of parallel and perpendicular red lines and of black circles, which are giving a geometric pattern of repeating, overlapping circles of equal radii on the two-dimensional planar surface.

\section{References}

[1] Sparavigna, A. C. and Baldi, M. M. (2016). Overlapping Circles Grid Drawn with Compass and Straightedge on an Egyptian Artifact of 14th Century BC. Non-Western Philosophy eJournal, 8(3): March 21. Available <hal-01290897>

[2] Sparavigna, A.C. (2013). Number Pi from the Decorations of Ancient Artifacts. Archaeoastronomy and Ancient Technologies, 1(2): 40-47.

[3] Sparavigna, A.C. (2012). Hemaka's constant. arXiv preprint arXiv:1204.0914.

[4] Vv. Aa. (2016). Wikipedia. Minoan Civilization.

[5] Broodbank, C. and Strasser, T. (1991). Migrant farmers and the Neolithic colonisation of Crete. Antiquity, 65: 233-245.

[6] Roebuck, C. (1966). The world of ancient times, Charles Scribner's Sons: New York.

[7] Welwei, K-W. (2002). Die Griechische Frühzeit, C.H. Beck, München.

[8] Luce, J.V. (1976). La Fine di Atlantide. Nuove luci su una antica leggenda. Grandi Tascabili Economici Newton.

[9] Angelakis, A., Koutsoyiannis, D., and Papanicolaou, P. (2012). On the Geometry of the Minoan Water Conduits, IWA Specialized Conference on Water \& Wastewater Technologies in Ancient Civilizations, Istanbul, Turkey, 22-24 March 2012.

[10] Papaodysseus, C., Panagopoulos, Th., Exarhos, M., Fragoulis, D., Roussopoulos, G., Rousopoulos, P., Galanopoulos, G., Triantafillou, C., Vlachopoulos, A. and Doumas, C. (2006), Distinct, late Bronze Age (c.1650 bc) wall-painting from Akrotiti, Thera, comprising advanced geometrical patterns. Archaeometry, 48: 97-114. doi: 10.1111/j.1475-4754.2006.00245.x

[11] Ball, P. (2006). Were ancient Minoans centuries ahead of their time? Unprecedented mathematical knowledge found in Bronze Age wall paintings. Published online 28 February 2006, Nature. doi:10.1038/news060227-3,

[12] Papaodysseus, C., Panagopoulos, M., Rousopoulos, P., Galanopoulos, G. and Doumas, C. (2008). Geometric templates used in the Akrotiri (Thera) wall-paintings, Antiquity, 82: 401-408

[13] Vv. Aa. (2016). https://en.wikipedia.org/wiki/Minoan_frescoes_from_Tell_el-Daba

[14] Crowly, J. (1997). Geometry in Minoan design, in R. Laffineur \& P. Betancourt (ed.)TEXNH: craftsmen, craftswomen and craftsmanship in the Aegean Bronze Age. Volume I (Aegaeum 16): 81-91. Liege.

[15] Hawass, Z. (2002). Bibliotheca Alexandria, American Univ. in Cairo Press. 